Issue Date: January 9, 2019

Manuscript number: DLD-18-1104

Amendment Number: 02

Author: $C L B$.

\title{
Impact of Inflammatory Bowel Diseases on working life: a French
}

\section{nationwide survey}

Catherine Le Berre ${ }^{1,2}$ (MD), Laurent Peyrin-Biroulet ${ }^{2}$ (MD, PhD), Anne Buisson ${ }^{3}$, Alain Olympie $^{3}$, Marie-Hélène Ravel ${ }^{3}$, Christina Bienenfeld $^{4}$, Florent Gonzalez ${ }^{5}$ (MD)

1: Institut des Maladies de l'Appareil Digestif, Nantes University Hospital, France.

2: Inserm U954 and Department of Gastroenterology, Nancy University Hospital, Université de Lorraine, France.

${ }^{3}$ : AFA, Paris, France.

${ }^{4}:$ IFOP, Paris, France.

5: Department of Gastroenterology, Grand-Sud Polyclinic, Nîmes, France.

\section{Corresponding author:}

Prof. Laurent Peyrin-Biroulet

Inserm U954 and Department of Gastroenterology

Nancy University Hospital, Université de Lorraine

1 Allée du Morvan, 54511 Vandœuvre-lès-Nancy, France

Tel +33 383153661

Fax +33383153633

peyrinbiroulet@gmail.com 
Funding: This work was supported by Takeda [grant to IFOP].

Electronic word count: $3,332$. 


\begin{abstract}
Background: Inflammatory bowel diseases (IBD) affect working-age patients. Data was lacking concerning the impact on working life.
\end{abstract}

Aims: The French IBD patient association conducted a nationwide survey to assess the burden of IBD at work.

Methods: An online survey was performed in 2016, targeting IBD patients working or having worked previously. The results were compared to those observed in the general population.

Results: Data from 1,410 IBD patients were analyzed (62\% Crohn's disease, 35\% ulcerative colitis). Four-fifth of respondents were actively employed. Half of them stated that working with IBD was a problem. Compared to the general population, IBD employees had higher rates of permanent contracts, public employment but also of part-time contracts, and highly graduated patients were less likely to reach high qualified jobs. Among the disabling symptoms at work, fatigue was the most frequent (41\%) followed by diarrhea (25\%) and fecal incontinence (18\%). Despite these difficulties, $76 \%$ were satisfied with their job. Most patients shared their IBD diagnosis with their colleagues, but $25 \%$ of them regretted it.

Conclusion: IBD has a strong negative impact on working life. While work satisfaction remains high, IBD affects career plans, highlighting the need for supporting measures to improve patients' work experience.

Key words: Crohn's disease; Ulcerative colitis; Burden; Professional life. 


\section{Introduction}

Inflammatory bowel diseases (IBD) are chronic disorders responsible for many digestive symptoms. Extra-intestinal manifestations (EIMs) are also common in both Crohn' s disease (CD) and ulcerative colitis (UC) [1]. Consequently, IBD can affect psychological, family, social and professional dimensions of patients' life, leading to poor quality of life [2,3], and disability [4]. Fatigue is one of the well-known factors involved [5,6].

In France, approximately 220,000 persons suffer from IBD, with a peak onset of 15-35 years of age [7], and many of them carry out an occupational activity. Few studies have already investigated the impact that IBD can have on patients' ability to work, but mainly as part of a more overall quality of life or disability assessment $[8,9]$. The Work Productivity and Activity Impairment Questionnaire (WPAI) is a generic tool specifically devoted to work disability $[10,11]$. It has been used in some IBD studies [12-14], demonstrating that both UC and $\mathrm{CD}$ can have a high impact on work productivity. Furthermore, it has been showed that work disability can lead to heavy indirect costs in IBD patients $[15,16]$.

However, data was still lacking concerning a more detailed patients' perception of the disease-related burden at work. In this respect, the French national IBD patients' association, called Association François Aupetit (AFA), has performed, in collaboration with medical experts, a nationwide survey to assess the issues faced by IBD patients at work. 


\section{Patients and methods}

\section{Study design}

The survey was designed in three phases: a qualitative phase enabling the construction of the questionnaire, a quantitative online survey, followed by a last qualitative step (focus groups). Here we present the results of the quantitative survey. The online survey was posted on the AFA website. The AFA communicated about the study via their magazine, and on Facebook and Twitter. This phase was conducted over 4 weeks from March to April 2016, targeting both AFA and non-AFA affiliated patients. Patients of both sexes, aged over 18, with an established diagnosis of IBD (CD, UC or IBD unclassified), currently working or having worked previously, were qualified to respond to the survey. Questionnaires with unfilled items were removed from the sample. The objective was to collect at least 1,000 filled-in questionnaires.

The questionnaire included 68 questions in total (see Supplementary Material). Sociodemographic data were first collected including: gender, age, region of residence, last completed degree, family status. Clinical data were also collected including: type of IBD, disease duration, evolutionary course, previous and ongoing disease-related treatments, history of intestinal resection, and presence of stoma. Patients had to self-evaluate disease severity thanks to a semi-quantitative 3-grade scale broken down as "mild", "moderate" or "severe". They also had to determine the frequency of flare-ups as defined by recurrence of digestive and/or extra-intestinal symptoms. Twenty-four questions assessed patient's former and present professional activity and the impact of IBD on their professional career. Work satisfaction was defined on a 4-grade scale broken down as: "very satisfied", "satisfied", "not very satisfied", "not at all satisfied", likewise optimism about professional future which could be defined as "very optimistic", "optimistic", "pessimistic", "very pessimistic". Seven questions focused on the communication about IBD at work, and the last 17 questions 
assessed the consequences of IBD on the ability to work and perform regular activities, including the five questions of the WPAI questionnaire over the past seven days.

\section{Data analysis}

Categorical variables were described by percentages and continuous variables by mean \pm standard deviation (SD).

WPAI scores measuring IBD patients' work and activity over the past 7 days were calculated, broken down as follows: WPAI 1: absenteeism rate; WPAI 2: efficiency loss rate (or presenteeism); WPAI 3: productivity loss rate (absenteeism and presenteeism); WPAI 4: overall activity impairment. Each WPAI sub-score ranges from 0 to $100 \%$.

The results were compared to those observed in the general population, derived from nationwide surveys performed by the "Institut Français de l'Opinion Publique" (IFOP). Quota on age, gender, region and profession were used to ensure the representativeness of the sample.

A segmentation (or classification) analysis was performed based on questionnaire replies in order to identify different typological profiles of IBD patients according to respondents' perception of their disease and its impact on their professional life. Classification - also called typology - is part of the advanced analytics tools that are used for decades in research, especially market research. The aim is to identify, through the analysis of multiple variables, study subgroups or clusters characterized by specific attitudes or behaviors. The benefit of using this type of analysis is that it summarizes an important amount of data collected. Statistically speaking, the aim of this classification is to create subgroups within a group through minimizing the intra-group variance (to create subgroups that are as homogeneous as possible) and to maximize inter-group variance (to create subgroups that are as different as possible from each other). For this project, the "classical typology" program on the analytical 
software Coheric Analytics SPAD ${ }^{\circledR}$ has been used. The technique involves a sequence of two multivariate statistical techniques: a multiple correspondence analysis of variables (MCA), followed by the clustering of respondents in several subgroups according to the approach names "mixed classification" that uses the WARD method and the K-MEANS cluster analysis.

\section{Ethics approval and informed consent}

All patients gave their informed consent when participating in the web-based survey. This survey was declared to the "Commission Nationale Informatique et Libertés" (CNIL). 


\section{Results}

\section{Respondents' characteristics}

\section{Demographic and clinical characteristics}

Over one month, 1,410 French IBD patients responded to the online survey. Among them, $60 \%$ were affiliated to the AFA. Demographic and clinical characteristics are summarized in Table 1. Twenty-seven percent were active smokers, and $16 \%$ were taking antidepressants or anxiolytics.

\section{Socio-professional characteristics}

Socio-professional characteristics are summarized in Table 2. Forty-one percent of all respondents (44\% of male respondents, $40 \%$ of female respondents) had a high school education background as compared to $25 \%$ in the general French population (27\% of male population, $24 \%$ of female population). The main professional sectors included health and social activities $(21 \%)$, services (14\%), trade (12\%) and industry (8\%).

\section{Descriptive results}

This part of the analysis focuses on respondents working at the moment of the survey $(n=1126)$.

\section{IBD patients seek job security but a full-time workload can be difficult}

Compared to the general population, actively employed respondents had higher rates of permanent work contracts and public employment, but also a higher rate of part-time contracts (Table 2). In average, IBD employees had been working in $3.4( \pm 2.7)$ different companies. More than half of them $(61 \%)$ had a stable professional course, i.e. a mean stay in 
the same company $\geq 3$ years for those with $<10$ years of professional experience, or $\geq 5$ years for those with $\geq 10$ years of experience.

\section{IBD impacts patients' career}

Many respondents declared that IBD changed their original career plan: $15 \%$ had to renounce to their initial choice, $24 \%$ chose a job they adjusted according to their disease. IBD patients with high degree of education accessed less frequently to highly skilled jobs than the general population (39\% versus $64 \%$ ). Thirty-nine percent also declared that their disease induced changes in the course of their career: among them, $25 \%$ felt that the choice of jobs was limited, $15 \%$ considered that IBD was a barrier to get a job, $11 \%$ declared having been dismissed because of IBD. Forty-five percent of respondents declared that IBD restricted their career development, and $43 \%$ asserted that their disease prevented them from fulfilling missions they should have been able to perform. Moreover, 68\% thought they had to push themselves beyond their professional limits and $49 \%$ declared that their career had become a second priority because of IBD. Overall, half of respondents stated that living with IBD at work was a problem. Only $37 \%$ affirmed that they encountered no career difficulties at all, $19 \%$ that they had no impact on their working life.

\section{Main symptoms impacting working life}

Fatigue was the most frequent of these symptoms (41\%) followed by diarrhea (25\%) and fecal incontinence (18\%). Pain and anxiety and/or depression were less frequent, reported by $10 \%$ and $3 \%$ of respondents, respectively.

Diarrhea and fecal incontinence episodes could be highly problematic, both at work and in public transport. Therefore, $75 \%$ of respondents chose to drive to work, and three-quarters of them stayed in a workplace close to home: $77 \%$ had less than one hour's commuting-time 
versus $65 \%$ in the general population. According to respondents, all these symptoms could also be responsible for indirect consequences on work productivity, such as a slower working pace and a perceived degraded quality of work.

\section{Optimism about professional future and job satisfaction}

More than half of respondents (59\%) were optimistic about their professional future, as compared to $66 \%$ of the general population. Seventy-two percent felt that their chances of finding a new job would be low; among them, $80 \%$ thought that this would be, completely or partially, related to IBD.

However, $76 \%$ of respondents were generally satisfied with their occupational situation, which was similar to the general population (74\%), but $80 \%$ of dissatisfied patients attributed it to IBD. Overall, IBD patients had a better perception of their professional situation than the general population, except for three selected items: work-related stress (68\% versus 54\%), balance between working and personal lives $(66 \%$ of satisfied respondents versus $75 \%$ of the general population), and safety conditions at work (57\% of satisfied respondents versus $65 \%$ of the general population).

\section{Informing colleagues about IBD}

Most respondents shared their IBD diagnosis with their superiors (immediate superior: 74\%, indirect supervisors: 57\%), mainly to justify their frequent sick leaves. The human resources manager (46\%), the staff representative (19\%) and the union representative (18\%) were less frequently informed. Figure 1 illustrates superiors' reaction after the announcement of the diagnosis. 
Most patients also communicated with their colleagues (closest colleagues: 85\%, others: $26 \%$ ), who reacted in a positive way for the majority of them. Figure 2 summarizes colleagues' reactions after receiving IBD diagnosis.

Eighty-four percent of respondents informed their occupational physician about their IBD, but only $67 \%$ of them were satisfied with the solutions that have been proposed.

Of the $89 \%$ of respondents who shared the IBD diagnosis in their working environment, $25 \%$ regretted having done so.

\section{WPAI scores}

While absenteeism rate (WPAI 1) was low at $11 \%$, efficiency loss rate (WPAI 2) and productivity loss rate (WPAI 3) were more important, respectively $34 \%$ and $36 \%$. Overall activity impairment (WPAI 4) was relatively high (47\%). WPAI scores were proportional to the disease severity (Table 3).

\section{Respondents' profiles}

Five typological profiles were identified among the respondents.

The "fighters" (18\%): patients with severe IBD who control it completely despite heavy symptoms. They are elder people with a stable job.

The "positives" (24\%): patients with moderate IBD who cope well with their disease despite the difficulties they face. They are quite young, not yet stable in their job, but have a permanent full-time contract.

The "spared" (16\%): patients with mild IBD without any impact on their professional life. They are quite young, with high degree of education, and have a permanent full-time contract. These three groups are satisfied with their professional life and optimistic about their future. 
The "vulnerables" (22\%): patients with severe IBD with important impact on their professional life. They encountered professional difficulties to such an extent that they had to change their career orientation.

The "outcasts" (20\%): patients with severe IBD who completely disrupted their professional life. Most of them are unemployed.

The two latter groups are dissatisfied with their professional life and are pessimistic about their future. They are in a precarious situation.

\section{Patients' rights: the disabled worker status}

The majority of respondents $(82 \%)$ felt that they were poorly informed about their rights as workers with a chronic disease. More than half of respondents $(68 \%)$ nonetheless knew that they had the right to get a disabled worker status, but only $29 \%$ of them were actually aware of the benefits that this status could provide. Almost three-quarters of respondents $(72 \%)$ already had $(53 \%)$ or wanted $(19 \%)$ to get this specific status while $28 \%$ rejected it.

\section{Key improvements expected by IBD patients at work}

Most respondents wanted their job to be adjusted if needed (65\%) and demanded more flexibility in the management of their working hours $(64 \%), 60 \%$ requested a more easily accessible "therapeutic part-time" employment and 58\% would like to do home-based telework. Sixty-one percent asked for large information campaigns reaching out to all professional workers; the same proportion would like to have their medical examinations during working time. 


\section{Discussion}

To the best of our knowledge, this survey is the first study to investigate, exclusively and in great detail, the impact of IBD on working life in a large nationwide cohort of 1,410 patients. We showed that IBD can affect career plans and work productivity. IBD patients often complain about fatigue and work-related stress, although most patients remain satisfied with their job.

Some of our results are consistent with previous studies, especially the BIRD study, recently performed in a French nationwide cohort of 1,185 IBD patients, that assessed all dimensions of patient-reported outcomes (PROs) [4]. However, the BIRD study did not explore in depth the impact of IBD on working life, only focusing on WPAI scores. This patient population was similar to ours, the only differences being the proportion of women and the median age, respectively lower (61.5\%) and higher (45 years old).

The WPAI scores were not exactly similar in both cohorts, but the larger proportion of women might explain the higher scores in our cohort, as the female gender has been described as a factor associated with work disability $[4,17]$.

Fatigue emerged as a major symptom in both studies: in our survey $41 \%$ of actively employed respondents reported fatigue as the most disabling symptom at work, while $47.4 \%$ complained of overall tiredness in the BIRD study, with a strong inverse correlation between overall work impairment and the FACIT-F (Functional Assessment of Chronic Illness Therapy-Fatigue) score. This finding is also consistent with a systematic review published in 2010, reporting fatigue in about $45 \%$ of patients with IBD in remission [5]. In an American study, the prevalence of fatigue was lower $(26.4 \%)$, but fatigued patients reported more work impairment [6]. 
Beyond confirming this data, our survey explored other larger dimensions of IBD patients' working life. It appeared that they seek more secure professional course than the general population, as respondents had a higher rate of permanent work contracts and public employment. In parallel, they have a higher rate of part-time contracts, reflecting the difficulties they face in assuming a full-time workload. This is consistent with the results of a Dutch study [18].

Our survey also investigated the symptoms that specifically affect patients' working life. Apart from fatigue, diarrhea and incontinence appeared to be extremely disabling, leading patients to set up avoiding strategies. Another study showed that IBD patients have to develop strategies and environmental supports at work [19]. According to patients, all these symptoms could also impact their work productivity, as confirmed in another study by De Boer et al. [20]. In the same vein, our study also demonstrated that work disability is proportional to inflammatory bowel disease severity, as it has already been shown in rheumatology for arthritis [21-25], and in pneumology for chronic obstructive pulmonary disease [26-28] and asthma $[29,30]$.

Despite all these negative impacts, most patients in our cohort reported a high degree of satisfaction concerning their job. However, work-related stress was more frequently reported by IBD patients as compared to the general population. Stress at work is reported in other publications but data is not homogenous. In a Swiss cohort of more than 1,500 IBD patients, the prevalence of job stress was remarkably low (5.7\%), but three factors were associated with a higher level: female gender, full-time contract, and extra-intestinal manifestations [31]. In a Canadian survey, IBD was rated as a highly frequent source of stress by $20-30 \%$ of patients with persistently active symptoms compared to $1-2 \%$ of patients in clinical remission, however work, as well as finances and family were equal sources of stress [32]. 
Our study identified five typological profiles, showing that IBD patients may have very different work experiences, half of them being slightly affected by the disease in their working life, while the other half is pessimistic and dissatisfied with both professional and personal lives. This finding confirms that a stable employment is a key driver of quality of life in IBD patients, as it has already been described in other studies [20,33].

This survey also demonstrated that most IBD patients communicate about their disease with their hierarchy and colleagues. Although the reaction was mostly supportive, about one-fifth of patients experienced a negative reaction, highlighting the need for a better understanding of IBD in companies. In addition to large information campaigns to the attention of professional workers, this survey reports other concrete needs that patients expressed to improve their working condition, such as an increased flexibility in their job, and a more appropriate medical care at work.

Some parameters were nevertheless not or little investigated in this survey. Our study did not explore factors associated with productivity loss as it was outside the scope of the research. However, this data is available from other publications. A recent review identified eight factors associated with work disability: extreme ages, female gender, lower education, disease activity, disease course (penetrating and perianal disease), previous surgery, but also comorbidities and corticosteroid use [17]. Another study conducted in a Hungarian cohort of 443 IBD patients confirmed that young age, previous surgery and arthralgia are associated with a higher risk of disability pension [34].

Moreover, most patients now receive biological treatments. In our survey, $41 \%$ of respondents received anti-TNF treatments. However, the correlation between these treatments and patients' working experience was not investigated, while several publications reported positive effects of these treatments on work productivity [35-40]. 
Finally, it should be noted that selection and participation bias might be quite significant in this type of web-based survey. Indeed, our cohort included a vast majority of female respondents with a mean age of 38 years old, and $80 \%$ of them assessed disease severity as moderate or severe. This sample of respondents may not be representative of the overall IBD population as they might possess certain traits which potentially result in biased estimates. In addition, this survey is based on a French population and it may be difficult to extrapolate our results to other countries, all the more so as our cohort represents only $0.6 \%$ of the 220,000 people suffering from IBD in France.

In conclusion, this survey assesses in depth the impact of IBD on working life, providing data about patients' perception of their professional life. Although most patients are satisfied with their job, IBD may affect career plans, work productivity, and induce work stress. Fatigue is the most disabling symptom. Supporting measures are needed to improve patients' work experience. 


\section{Author contributions}

C.L.B.: drafting of the final version of the article and literature review; L.P-B.: study design and supervision; A.B, A.O., M.-H.R., C.B., F.G.: patient recruitment, data collection and analysis, writing up of the first draft of the paper. All named authors have read and approved the final manuscript. 


\section{References}

[1] Levine JS, Burakoff R. Extraintestinal Manifestations of Inflammatory Bowel Disease. Gastroenterol Hepatol (N Y) 2011;7:235-41.

[2] Casellas F, López-Vivancos J, Vergara M, Malagelada J. Impact of inflammatory bowel disease on health-related quality of life. Dig Dis 1999;17:208-18. doi:10.1159/000016938.

[3] Lönnfors S, Vermeire S, Greco M, Hommes D, Bell C, Avedano L. IBD and healthrelated quality of life -- discovering the true impact. J Crohns Colitis 2014;8:1281-6. doi:10.1016/j.crohns.2014.03.005.

[4] Williet N, Sarter H, Gower-Rousseau C, Adrianjafy C, Olympie A, Buisson A, et al. Patient-reported Outcomes in a French Nationwide Survey of Inflammatory Bowel Disease Patients. J Crohns Colitis 2017;11:165-74. doi:10.1093/ecco-jcc/jjw145.

[5] van Langenberg DR, Gibson PR. Systematic review: fatigue in inflammatory bowel disease. Aliment Pharmacol Ther 2010;32:131-43. doi:10.1111/j.1365-2036.2010.04347.x.

[6] Cohen BL, Zoëga H, Shah SA, Leleiko N, Lidofsky S, Bright R, et al. Fatigue is highly associated with poor health-related quality of life, disability and depression in newlydiagnosed patients with inflammatory bowel disease, independent of disease activity. Aliment Pharmacol Ther 2014;39:811-22. doi:10.1111/apt.12659.

[7] Gower-Rousseau C, Vasseur F, Fumery M, Savoye G, Salleron J, Dauchet L, et al. Epidemiology of inflammatory bowel diseases: New insights from a French population-based registry (EPIMAD). Digestive and Liver Disease 2013;45:89-94. doi:10.1016/j.dld.2012.09.005.

[8] Ananthakrishnan AN, Weber LR, Knox JF, Skaros S, Emmons J, Lundeen S, et al. Permanent work disability in Crohn's disease. Am J Gastroenterol 2008;103:154-61. doi:10.1111/j.1572-0241.2007.01561.x. 
[9] Høivik ML, Moum B, Solberg IC, Henriksen M, Cvancarova M, Bernklev T, et al. Work disability in inflammatory bowel disease patients 10 years after disease onset: results from the IBSEN Study. Gut 2013;62:368-75. doi:10.1136/gutjnl-2012-302311.

[10] Reilly MC, Zbrozek AS, Dukes EM. The validity and reproducibility of a work productivity and activity impairment instrument. Pharmacoeconomics 1993;4:353-65.

[11] Reilly MC, Gerlier L, Brabant Y, Brown M. Validity, reliability, and responsiveness of the work productivity and activity impairment questionnaire in Crohn's disease. Clin Ther 2008;30:393-404. doi:10.1016/j.clinthera.2008.02.016.

[12] Gibson PR, Vaizey C, Black CM, Nicholls R, Weston AR, Bampton P, et al. Relationship between disease severity and quality of life and assessment of health care utilization and cost for ulcerative colitis in Australia: a cross-sectional, observational study. $\mathbf{J}$ Crohns Colitis 2014;8:598-606. doi:10.1016/j.crohns.2013.11.017.

[13] Steenholdt C, Brynskov J, Thomsen OØ, Munck LK, Christensen LA, Pedersen G, et al. Implications of Infliximab Treatment Failure and Influence of Personalized Treatment on Patient-reported Health-related Quality of Life and Productivity Outcomes in Crohn's Disease. J Crohns Colitis 2015;9:1032-42. doi:10.1093/ecco-jcc/jjv139.

[14] Van Assche G, Peyrin-Biroulet L, Sturm A, Gisbert JP, Gaya DR, Bokemeyer B, et al. Burden of disease and patient-reported outcomes in patients with moderate to severe ulcerative colitis in the last 12 months - Multicenter European cohort study. Dig Liver Dis 2016;48:592-600. doi:10.1016/j.dld.2016.01.011.

[15] Blomqvist P, Ekbom A. Inflammatory Bowel Diseases: Health Care and Costs in Sweden in 1994. Scandinavian Journal of Gastroenterology 1997;32:1134-9. doi:10.3109/00365529709002993. 
[16] Floyd DN, Langham S, Séverac HC, Levesque BG. The Economic and Quality-ofLife Burden of Crohn's Disease in Europe and the United States, 2000 to 2013: A Systematic Review. Digestive Diseases and Sciences 2015;60:299-312. doi:10.1007/s10620-014-3368-z.

[17] Büsch K, Sonnenberg A, Bansback N. Impact of Inflammatory Bowel Disease on Disability. Curr Gastroenterol Rep 2014;16:414. doi:10.1007/s11894-014-0414-0.

[18] Netjes JE, Rijken M. Labor participation among patients with inflammatory bowel disease. Inflamm Bowel Dis 2013;19:81-91. doi:10.1002/ibd.22921.

[19] Restall GJ, Simms AM, Walker JR, Graff LA, Sexton KA, Rogala L, et al. Understanding Work Experiences of People with Inflammatory Bowel Disease. Inflamm Bowel Dis 2016;22:1688-97. doi:10.1097/MIB.0000000000000826.

[20] De Boer AGEM, Bennebroek Evertsz' F, Stokkers PC, Bockting CL, Sanderman R, Hommes DW, et al. Employment status, difficulties at work and quality of life in inflammatory bowel disease patients. Eur J Gastroenterol Hepatol 2016;28:1130-6. doi:10.1097/MEG.0000000000000685.

[21] Chaparro Del Moral R, Rillo OL, Casalla L, Morón CB, Citera G, Cocco JAM, et al. Work productivity in rheumatoid arthritis: relationship with clinical and radiological features. Arthritis 2012;2012:137635. doi:10.1155/2012/137635.

[22] Bansback N, Zhang W, Walsh D, Kiely P, Williams R, Guh D, et al. Factors associated with absenteeism, presenteeism and activity impairment in patients in the first years of RA. Rheumatology (Oxford) 2012;51:375-84. doi:10.1093/rheumatology/ker385.

[23] Dibonaventura MD, Gupta S, McDonald M, Sadosky A, Pettitt D, Silverman S. Impact of self-rated osteoarthritis severity in an employed population: cross-sectional analysis of data from the national health and wellness survey. Health Qual Life Outcomes 2012;10:30. doi:10.1186/1477-7525-10-30. 
[24] Tillett W, Shaddick G, Askari A, Cooper A, Creamer P, Clunie G, et al. Factors influencing work disability in psoriatic arthritis: first results from a large UK multicentre study. Rheumatology (Oxford) 2015;54:157-62. doi:10.1093/rheumatology/keu264.

[25] Haglund E, Petersson IF, Bremander A, Bergman S. Predictors of presenteeism and activity impairment outside work in patients with spondyloarthritis. J Occup Rehabil 2015;25:288-95. doi:10.1007/s10926-014-9537-2.

[26] Solem CT, Sun SX, Sudharshan L, Macahilig C, Katyal M, Gao X. Exacerbationrelated impairment of quality of life and work productivity in severe and very severe chronic obstructive pulmonary disease. Int J Chron Obstruct Pulmon Dis 2013;8:641-52. doi:10.2147/COPD.S51245.

[27] Dhamane AD, Witt EA, Su J. Associations Between COPD Severity and Work Productivity, Health-Related Quality of Life, and Health Care Resource Use: A CrossSectional Analysis of National Survey Data. J Occup Environ Med 2016;58:e191-197. doi:10.1097/JOM.0000000000000735.

[28] Ding B, Small M, Bergström G, Holmgren U. COPD symptom burden: impact on health care resource utilization, and work and activity impairment. Int $\mathbf{J}$ Chron Obstruct Pulmon Dis 2017;12:677-89. doi:10.2147/COPD.S123896.

[29] Chen H, Blanc PD, Hayden ML, Bleecker ER, Chawla A, Lee JH, et al. Assessing productivity loss and activity impairment in severe or difficult-to-treat asthma. Value Health 2008;11:231-9. doi:10.1111/j.1524-4733.2007.00229.x.

[30] Vietri J, Burslem K, Su J. Poor Asthma control among US workers: health-related quality of life, work impairment, and health care use. J Occup Environ Med 2014;56:425-30. doi:10.1097/JOM.0000000000000123. 
[31] Schreiner P, Biedermann L, Rossel J-B, Rogler G, Pittet V, von Känel R, et al. Prevalence and Determinants of Job Stress in Patients with Inflammatory Bowel Disease. Inflamm Bowel Dis 2017;23:310-7. doi:10.1097/MIB.0000000000001012.

[32] Bernstein MT, Targownik LE, Sexton KA, Graff LA, Miller N, Walker JR. Assessing the Relationship between Sources of Stress and Symptom Changes among Persons with IBD over Time: A Prospective Study. Can J Gastroenterol Hepatol 2016;2016. doi:10.1155/2016/1681507.

[33] Bernklev T, Jahnsen J, Henriksen M, Lygren I, Aadland E, Sauar J, et al. Relationship between sick leave, unemployment, disability, and health-related quality of life in patients with inflammatory bowel disease. Inflamm Bowel Dis 2006;12:402-12. doi:10.1097/01.MIB.0000218762.61217.4a.

[34] Mandel MD, Michael MD, Bálint A, Lovász BD, Gulácsi L, Strbák B, et al. Work disability and productivity loss in patients with inflammatory bowel diseases in Hungary in the era of biologics. Eur J Health Econ 2014;15 Suppl 1:S121-128. doi:10.1007/s10198-0140603-7.

[35] Feagan BG, Reilly MC, Gerlier L, Brabant Y, Brown M, Schreiber S. Clinical trial: the effects of certolizumab pegol therapy on work productivity in patients with moderate-tosevere Crohn's disease in the PRECiSE 2 study. Aliment Pharmacol Ther 2010;31:1276-85. doi:10.1111/j.1365-2036.2010.04303.x.

[36] Feagan BG, Sandborn WJ, Wolf DC, Coteur G, Purcaru O, Brabant Y, et al. Randomised clinical trial: improvement in health outcomes with certolizumab pegol in patients with active Crohn's disease with prior loss of response to infliximab. Aliment Pharmacol Ther 2011;33:541-50. doi:10.1111/j.1365-2036.2010.04568.x.

[37] Lichtiger S, Binion DG, Wolf DC, Present DH, Bensimon AG, Wu E, et al. The CHOICE trial: adalimumab demonstrates safety, fistula healing, improved quality of life and 
increased work productivity in patients with Crohn's disease who failed prior infliximab therapy. Aliment Pharmacol Ther 2010;32:1228-39. doi:10.1111/j.1365-2036.2010.04466.x. [38] Panaccione R, Loftus EV, Binion D, McHugh K, Alam S, Chen N, et al. Efficacy and safety of adalimumab in Canadian patients with moderate to severe Crohn's disease: results of the Adalimumab in Canadian SubjeCts with ModErate to Severe Crohn's DiseaSe (ACCESS) trial. Can J Gastroenterol 2011;25:419-25.

[39] Louis E, Löfberg R, Reinisch W, Camez A, Yang M, Pollack PF, et al. Adalimumab improves patient-reported outcomes and reduces indirect costs in patients with moderate to severe Crohn's disease: results from the CARE trial. J Crohns Colitis 2013;7:34-43. doi:10.1016/j.crohns.2012.02.017.

[40] Binion DG, Louis E, Oldenburg B, Mulani P, Bensimon AG, Yang M, et al. Effect of adalimumab on work productivity and indirect costs in moderate to severe Crohn's disease: a meta-analysis. Can J Gastroenterol 2011;25:492-6. 


\section{Acknowledgements}

We thank Takeda for the grant provided to this study. 


\section{Figure legends}

Figure 1. Superiors' reaction after receiving patient's IBD diagnosis.

The reaction was mostly supportive: superiors assured the patient of their support in $46 \%$ of cases, expressed concern in $28 \%$ or saw an inherent advantage in $16 \%$ of cases, and $16 \%$ of respondents were proposed to reorganize their work station. However, some of these patients experienced a negative reaction from their hierarchy (18\%): $8 \%$ were subject to harassment, $6 \%$ were shunted into a siding, $6 \%$ had to work in a different work station, and even $7 \%$ were dismissed ( $3 \%$ because of IBD, $4 \%$ for another reason).

${ }^{\mathrm{a}}$ : Patients could have more than one response.

Figure 2. Colleagues' reaction after receiving patient's IBD diagnosis.

Colleagues reacted in a positive way for the majority of them: $67 \%$ accepted it with ease, and $45 \%$ assured the patient of their support. However, $21 \%$ of respondents received a negative feedback from their co-workers: people's attitudes to the patient have changed in $17 \%$ of cases, $6 \%$ of patients suffered from malicious acts, and $3 \%$ felt disregarded.

a: Patients could have more than one response. 


\section{SUPERIORS}

\section{$46 \%$ Superiors assured the patient of their support}

\section{8\% Superiors expressed concern}

$16 \%$ Superiors saw an inherent advantage

$16 \%$ Superiors proposed to reorganize patient's work station

$8 \%$ Subject to harassment

$6 \% \quad$ Shunted into a siding

6\% Had to work in a different work station 


\section{COLLEAGUES}

\section{$67 \% \quad$ Colleagues accepted it with ease}

45\% Colleagues assured the patient of their support

$17 \% \quad$ People's attitudes to the patient have changed

6\% Felt disregarded

$3 \% \quad$ Suffered from malicious acts

Negative reactions

$21 \%$ 
Manuscript number: DLD-18-1104

Table 1. Demographic and clinical characteristics of respondents $(n=1410)$.

\begin{tabular}{ll}
\hline Demographic and clinical data & Total $(n=1410)$
\end{tabular}

Sex, n (\%)

- Female

1070 (76)

Type of IBD

- Crohn's disease, n (\%)

$875(62)$

- Ulcerative colitis, n (\%)

496 (35)

- $\quad$ IBD unclassified, n (\%)

39 (3)

Age (years), mean (SD)

$38(10.1)$

- 18-29 years old, n (\%)

297 (21)

- 30-39 years old, n (\%)

547 (39)

- 40-49 years old, n (\%)

$350(25)$

- 50-59 years old, n (\%)

175 (12)

- 60 years old and over, n (\%)

$41(3)$

Disease duration (years) $^{\mathrm{a}}$

- < 1 year, n $(\%)$

- $\quad 1-9$ years, $\mathrm{n}(\%)$

- > 10 years, n $(\%)$

$723(51)$

Disease activity $^{b}$

- $\quad$ Mild disease, n (\%) 203 (14)

- Moderate disease, n (\%) 748 (53)

- Severe disease, n (\%) 


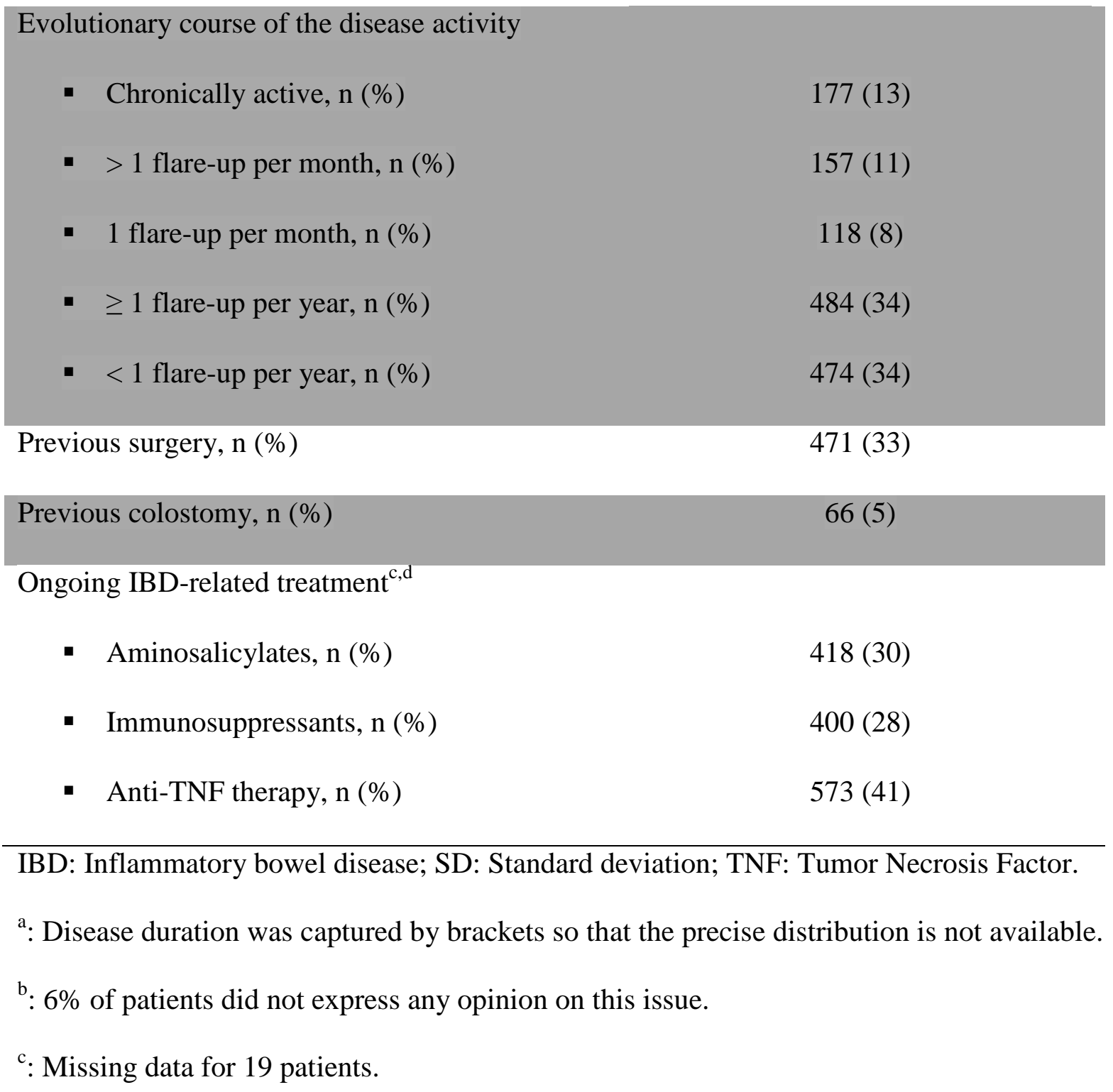


Manuscript number: DLD-18-1104

Table 2. Socio-professional characteristics of IBD respondents compared to the general population.

Socio-professional data IBD respondents General population ${ }^{\mathrm{a}}$

Professional status

- Actively employed, n (\%)

$1126(80)$

- Unemployed, n (\%)

- Disability leave, n (\%)

- $\quad$ Retired, n (\%)

- Without work for another reason, n (\%)

$100(7)$

Type of employment contract ${ }^{b}$

- Permanent contract, $\mathrm{n}(\%)$

$921(82)$

- Temporary contract, $\mathrm{n}(\%)$

$136(12)$

- Agency work (“interim”), n (\%)

9 (1)

2

- Without any contract, n (\%)

$60(5)$

Public employment, $\mathrm{n}(\%)^{\mathrm{b}}$

$411(37)$

29

Part-time contract, n $(\%)^{\mathrm{b}}$

$293(26)$

19

Work satisfaction ${ }^{\mathrm{b}}$

- Very satisfied, n (\%)

$171(15)$

- Satisfied, n (\%)

$685(61)$

- Dissatisfied, n (\%)

$270(24)$

26

IBD: Inflammatory bowel disease; IFOP: Institut Français de l'Opinion Publique.

a: Data from IFOP database. 
b: This part of the analysis focuses on respondents working at the moment of the survey $(n=1126)$. 
Manuscript number: DLD-18-1104

Table 3. Comparison of WPAI scores according to the self-perception of disease severity by the patient.

\begin{tabular}{|c|c|c|c|c|}
\hline WPAI scores & $\begin{array}{c}\text { Total } \\
(\mathrm{n}=1,336)^{\mathrm{a}}\end{array}$ & $\begin{array}{c}\text { Mild } \\
(n=203)\end{array}$ & $\begin{array}{l}\text { Moderate } \\
(n=748)\end{array}$ & $\begin{array}{l}\text { Severe } \\
(n=385)\end{array}$ \\
\hline WPAI 1: Absenteeism rate $(\%)$ & 10.9 & 5.8 & 9.8 & 15.2 \\
\hline WPAI 2: Efficiency loss rate (\%) & 34.3 & 25.4 & 32.6 & 42.7 \\
\hline WPAI 3: Productivity loss rate $(\%)$ & 36.0 & 26.1 & 34.4 & 44.4 \\
\hline WPAI 4: Overall activity impairment (\%) & 46.9 & 35.1 & 45.5 & 56.0 \\
\hline
\end{tabular}

WPAI: Work Productivity and Activity Impairment Questionnaire.

a: $6 \%$ of patients did not express any opinion on this issue. 